\title{
Efficiency of endoscopy units can be improved with use of discrete event simulation modeling
}

Authors

Institutions
Bryan G. Sauer ${ }^{1}$, Kanwar P. Singh ${ }^{2}$, Barry L. Wagner², Matthew S. Vanden Hoek¹, Katherine Twilley², Steven M. Cohn', Vanessa M. Shami ${ }^{1}$, Andrew Y. Wang ${ }^{1}$

${ }^{1}$ Division of Gastroenterology and Hepatology, University of Virginia, Charlottesville, VA, USA

${ }^{2}$ University of Virginia Health System, Charlottesville, VA, USA submitted 30. March 2016 accepted after revision 22. August 2016

\section{Bibliography}

DOI http://dx.doi.org/

10.1055/s-0042-117217

Published online: 28.10.2016

Endoscopy International Open 2016; 04: E1140-E1145

(c) Georg Thieme Verlag KG

Stuttgart · New York

E-ISSN 2196-9736

Corresponding author

Bryan G. Sauer, MD

MSc (Clin Res)

Division of Gastroenterology and Hepatology

Box 800708

University of Virginia

Charlottesville

VA 22908

USA

Fax: +1-434-244-9410

bryansauer@virginia.edu
Background and study aims: The projected increased demand for health services obligates healthcare organizations to operate efficiently. Discrete event simulation (DES) is a modeling method that allows for optimization of systems through virtual testing of different configurations before implementation. The objective of this study was to identify strategies to improve the daily efficiencies of an endoscopy center with the use of DES.

Methods: We built a DES model of a five procedure room endoscopy unit at a tertiary-care university medical center. After validating the baseline model, we tested alternate configurations to run the endoscopy suite and evaluated outcomes associated with each change. The main outcome measures included adequate number of preparation and recovery rooms, blocked inflow, delay times, blocked outflows, and patient cycle time.

\section{Introduction}

\section{$\nabla$}

In today's era of healthcare, demand for health services continues to increase. In the coming years, it is estimated that 15 million more Americans will become eligible for Medicare [1]. Furthermore, the Patient Protection and Affordable Care Act is projected to expand health insurance coverage to more than 30 million Americans [2]. Despite this significant increase in demand, the number of medical facilities and physicians is not expected to increase concurrently. It is estimated that by 2020 , there will be a physician shortage of 91500 doctors [1]. It is therefore paramount that we evaluate and improve the efficiency in which healthcare is delivered.

Discrete event simulation (DES) is a flexible modeling method used extensively in the manufacturing industry to improve efficiency $[3,4]$. DES has recently been applied to the healthcare setting for tasks such as planning of operating room suites [5-7] and scheduling in primary care clin-
Results: Based on a sensitivity analysis, the adequate number of preparation rooms is eight and recovery rooms is nine for a five procedure room unit (total 3.4 preparation and recovery rooms per procedure room). Simple changes to procedure scheduling and patient arrival times led to a modest improvement in efficiency. Increasing the preparation/recovery rooms based on the sensitivity analysis led to significant improvements in efficiency.

Conclusions: By applying tools such as DES, we can model changes in an environment with complex interactions and find ways to improve the medical care we provide. DES is applicable to any endoscopy unit and would be particularly valuable to those who are trying to improve on the efficiency of care and patient experience.

ics [8]. More specific to gastroenterology, use of DES modeling has rarely been reported in endoscopy centers. One study recently reported the use of DES in a large colonoscopy suite to evaluate the global efficiency of the unit. They evaluated factors including endoscopist/room ratio, effect of turnover time, and patient wait times [9]. Others have used DES to reduce access times for endoscopy [10], estimate the cost of no-shows [11], and identify ways to improve overall efficiency [12]. More recently, DES was used to optimize efficiency and operations in a safety-net endoscopy center in California [13]. However, DES remains an underutilized tool in endoscopy centers [14]. With the increasing demand for endoscopic procedures, especially screening colonoscopies, improved efficiency is essential. We applied DES to an endoscopy suite with five procedure rooms at a large academic medical center.

Our goal was to analyze our endoscopy suite and identify ways to improve efficiency. We specifically wanted to decrease physician down-time 


\begin{tabular}{|c|c|c|c|}
\hline Procedure type & $\begin{array}{l}\text { Default scheduling } \\
\text { time for procedure, } \\
\text { min }\end{array}$ & $\begin{array}{l}\text { Average number } \\
\text { of procedures per } \\
\text { week }\end{array}$ & $\begin{array}{l}\text { Percentage of total } \\
\text { number of patients } \\
\text { performed per week }\end{array}$ \\
\hline Upper endoscopy (EGD) & 30 & 44 & \multirow{2}{*}{39} \\
\hline Endoscopic ultrasound (EGD/EUS) & 60 & 29 & \\
\hline Colonoscopy & 45 & 81 & 44 \\
\hline Liver biopsy & 240 & 3 & \multirow{2}{*}{5} \\
\hline Paracentesis & 120 & 6 & \\
\hline $\begin{array}{l}\text { Endoscopic retrograde } \\
\text { cholangiopancreatography (ERCP) }\end{array}$ & 60 & 21 & 12 \\
\hline
\end{tabular}

Table 1 Procedure scheduling practices and volumes, status quo.

EGD, esophagogastroduodenoscopy; EUS, endoscopic ultrasound.

\begin{tabular}{|c|c|c|}
\hline Processes & Average time, min & Process definition \\
\hline \multirow[t]{2}{*}{ Patient arrival and registration } & 19.76 & Patient arrival and registration \\
\hline & & Patient wait time until arrival in pre-procedure area \\
\hline \multirow[t]{5}{*}{ Pre-procedure } & 59.29 & Patient arrival in pre-procedure area \\
\hline & & Wait time before pre-procedure preparation \\
\hline & & Pre-procedure nurse assessment \\
\hline & & Pre-procedure physician consent \\
\hline & & Wait time before transfer to procedure room \\
\hline \multirow[t]{4}{*}{ Procedure } & 56.58 & Patient arrival in procedure room \\
\hline & & Procedure start to end \\
\hline & & Procedure end to patient departs procedure room \\
\hline & & Room clean-up for intake of next patient \\
\hline \multirow[t]{2}{*}{ Post-procedure } & 69.96 & Patient arrival in recovery area \\
\hline & & Patient discharge to endoscopy unit \\
\hline Total patient time & 205.59 & Patient arrival at discharge \\
\hline
\end{tabular}

Table 2 Description of actual patient experience across each individual queue derived from direct observation time stamps. and reduce instances of nursing staff leaving after 1900, all while not adversely impacting the patient experience. We also sought to evaluate the effect of adding an additional endoscopy room.

\section{Methods}

$\nabla$

\section{Endoscopy unit}

The endoscopy unit has five procedure rooms, five preparation rooms, and nine recovery rooms. The suite is expected to operate daily from 0700 to 1900 , with 0800 procedure start time. Physicians are assigned to one procedure room (physician to room ratio $1: 1$ ) for either a full or half-day. Four of the procedure rooms use conscious sedation provided by the gastroenterologist and perform predominantly upper endoscopy, endoscopic ultrasound, and colonoscopy. The other procedure room performs mainly endoscopic retrograde cholangiopancreatography (ERCP) under general anesthesia. Additionally, paracentesis and liver biopsies are performed regularly using one of the nine recovery rooms. The status quo scheduling practices and average procedure volumes were obtained through a billing database from January to June 2012 ( $\bullet$ Table 1 ).

\section{Baseline model}

A DES model of the endoscopy suite was initially created and subsequently validated. Observational data of endoscopy operations were collected on five random days between August 2011 and January 2012 through a manual time-stamp exercise during which times were documented by seven external observers. Data contained case mix including add-ons and no-shows, scheduling practices, activity times for each particular endoscopy case, and room utilization. Activity times for each procedure type (i.e. esophagogastroduodenoscopy (EGD), colonoscopy, ERCP, etc.) included numerous time stamps along each step of the endoscopy which were used to generate preparation, procedure, recovery, and wait times ( Table 2 ). Furthermore, the ratio of procedure type for each day was included in the model with probability distributions to account for daily variations ( $\bullet$ Table 1). The data were then used to create a simulation model using MedModel simulation software (ProModel Corporation, Orem, Utah, United States). Finally, the model was validated by running it and comparing various outcomes to those that were obtained during the observational process to ensure that the model was an accurate representation of actual procedure days. Additionally, the probability distributions for event times were separately sampled to verify that the distribution from the model matched the actual distribution from the data collection.

\section{Metrics evaluated}

After validating the baseline model, we divided the patient experience into three distinct queuing phases (Preparation, Procedure, and Recovery) ( $\bullet$ Fig. 1) and tested alternate configurations to run the endoscopy suite, including altering the schedule template, modifying patient arrival times, changing the procedure configuration, and adding preparation/recovery rooms.

Numerous metrics were evaluated including:

1. Sensitivity analysis of number of preparation/recovery rooms:

a) We performed a sensitivity analysis using the status quo model in order to ascertain the adequate number of preparation and recovery rooms required to reduce blocked inflow and outflow events.

2. Metrics to evaluate physician productivity:

a) Instances of blocked inflows: events when a physician is waiting for a patient in the procedure room but the patient 


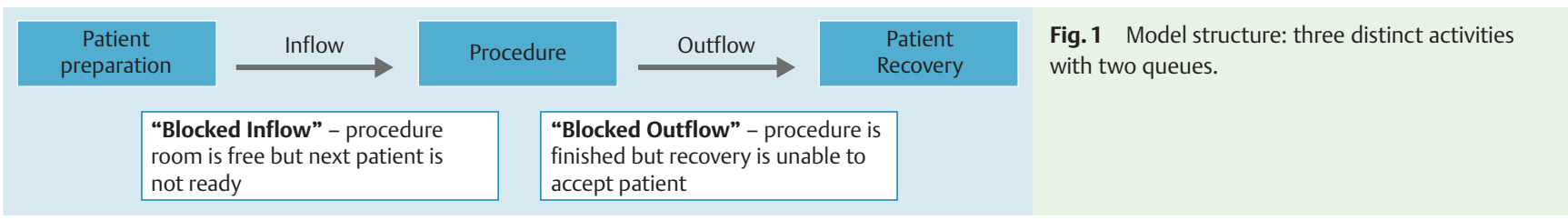

Table 3 Comparison of key metrics between selected scenarios.

\begin{tabular}{|c|c|c|c|c|c|c|c|}
\hline Key metrics & $\begin{array}{l}\text { Status } \\
\text { quo }\end{array}$ & $\begin{array}{l}\text { Scenario 1: } \\
\text { EGD moved } \\
\text { to first cases }\end{array}$ & $\begin{array}{l}\text { Scenario 2: } \\
\text { change in patient } \\
\text { arrival times (i.e. } \\
\text { arrive sooner) }\end{array}$ & $\begin{array}{l}\text { Scenario 3: } \\
\text { combination } \\
\text { of } 1 \text { and } 2\end{array}$ & $\begin{array}{l}\text { Scenario 4: } \\
\text { add } 3 \text { prep } \\
\text { rooms }\end{array}$ & $\begin{array}{l}\text { Scenario 5: } \\
\text { combination } \\
\text { of } 3 \text { and } 4\end{array}$ & $\begin{array}{l}\text { Theoretical } \\
\text { best case }\end{array}$ \\
\hline Blocked inflow per day, \% & 34.6 & 33.5 & 34.1 & 31.6 & 25.5 & 14.6 & 0 \\
\hline $\begin{array}{l}\text { Average delay during a blocked inflow, } \\
\text { min }\end{array}$ & 33.7 & 28.8 & 34.1 & 28.7 & 23.8 & 23.0 & 0 \\
\hline Blocked outflow per day, \% & 3.0 & 2.0 & 2.9 & 3.5 & 9.9 & 8.4 & 0 \\
\hline $\begin{array}{l}\text { Percentage of scheduled procedures } \\
\text { completed by } 1700, \%\end{array}$ & 92.9 & 93.3 & 93.1 & 95.0 & 96.0 & 96.1 & 96.7 \\
\hline Room utilization of last recovery room, \% & 22.6 & 20.1 & 21.3 & 20.3 & 30.1 & 31.7 & 0 \\
\hline Patients exiting past $1700(\%)$ & 17.4 & 14.8 & 17.7 & 12.8 & 11.8 & 10.6 & 7.7 \\
\hline Patients exiting past $1900, \%$ & 2.6 & 2.4 & 2.4 & 2.3 & 1.3 & 1.0 & 0.9 \\
\hline $\begin{array}{l}\text { Time from arrival in preparation room } \\
\text { to discharge, } \mathrm{min}\end{array}$ & 182.9 & 182.6 & 184.1 & 183.6 & 204.4 & 212.5 & 345.3 \\
\hline
\end{tabular}

EGD, esophagogastroduodenoscopy.

has not been fully prepped (after procedure room turnaround is complete).

b) Instances of blocked outflows: events when a procedure is completed but unable to move the patient out of the procedure room because a recovery room is not available.

c) Percentage of scheduled procedures completed by 1700 .

3. Metrics to evaluate suite efficiency:

a) Room utilization of the last recovery room per scenario tested.

b) Average number of patients in recovery at 1900 .

4. Metrics to evaluate patient experience:

a) Patient cycle time: Defined as the total processing time of a patient from the time a patient starts the pre-procedure intake for his/her scheduled procedure to the time of discharge from recovery room.

\section{Simulation}

We tested 35 alternate scenarios and simulated 20 cycles (i.e., 20 days for each scenario). We simulated scenarios that we considered practical and theoretical. We present several scenarios including the status quo, changes to scheduling practices, changes to patient arrival times, and alterations to the physical space to allow for increased preparation/recovery rooms. We also present a theoretical scenario whereby all possible restraints were removed including those presented by patients (i.e., arriving late), staff (i.e., not enough staff), and physical space (i.e., inadequate number of preparation and/or recovery rooms). The intention of the theoretical best-case scenario was to ascertain the limits at which the endoscopy unit could function. We also modeled the addition of an endoscopy room dedicated to advanced endoscopy (mainly ERCP).

\section{Results}

\section{Model validation}

The model was validated against 5 days of actual data with various outcomes for the actual days compared to the outcomes from the model. Furthermore, the model was re-validated 6 months into the project with 2 days of actual data. When comparing the model to the actual days in endoscopy, average patient cycle time (time of pre-procedure intake to discharge) was 181.4 minutes in the model whereas it was 185.8 minutes for the five actual procedure days. During validation, the model event processing times averaged \pm 4.2 minutes deviation from the actual times (for preparation, procedure, and recovery times). Additionally, model patient cycle times from "preparation start to exit" averaged a range of +14 minutes to -16 minutes deviation from actual times (on an average cycle time of 195 minutes). Based on these validation statistics and minimal deviation of the model from actual days, the model was felt to be accurate and valid.

\section{Status quo}

In modeling of the current operations of the endoscopy unit, the average patient time from patient preparation to discharge was approximately 183 minutes (includes all procedures). Blocking inflow events occurred $35 \%$ of the time, and the time of these events averaged 34 minutes $(\boldsymbol{\bullet}$ Table $\mathbf{3})$.

\section{Sensitivity analysis on number of preparation and recovery rooms}

We ran the model with various numbers of preparation and recovery rooms to evaluate the effect on blocked inflow and blocked outflow events ( $\bullet$ Fig.2). The threshold to decrease blocked inflow events to less than $15 \%$ was eight preparation rooms. The threshold to have fewer than $5 \%$ blocked outflow events was nine recovery rooms. As a unit has five procedure rooms, that is a preparation/endoscopy room ratio of 1.6 and a 

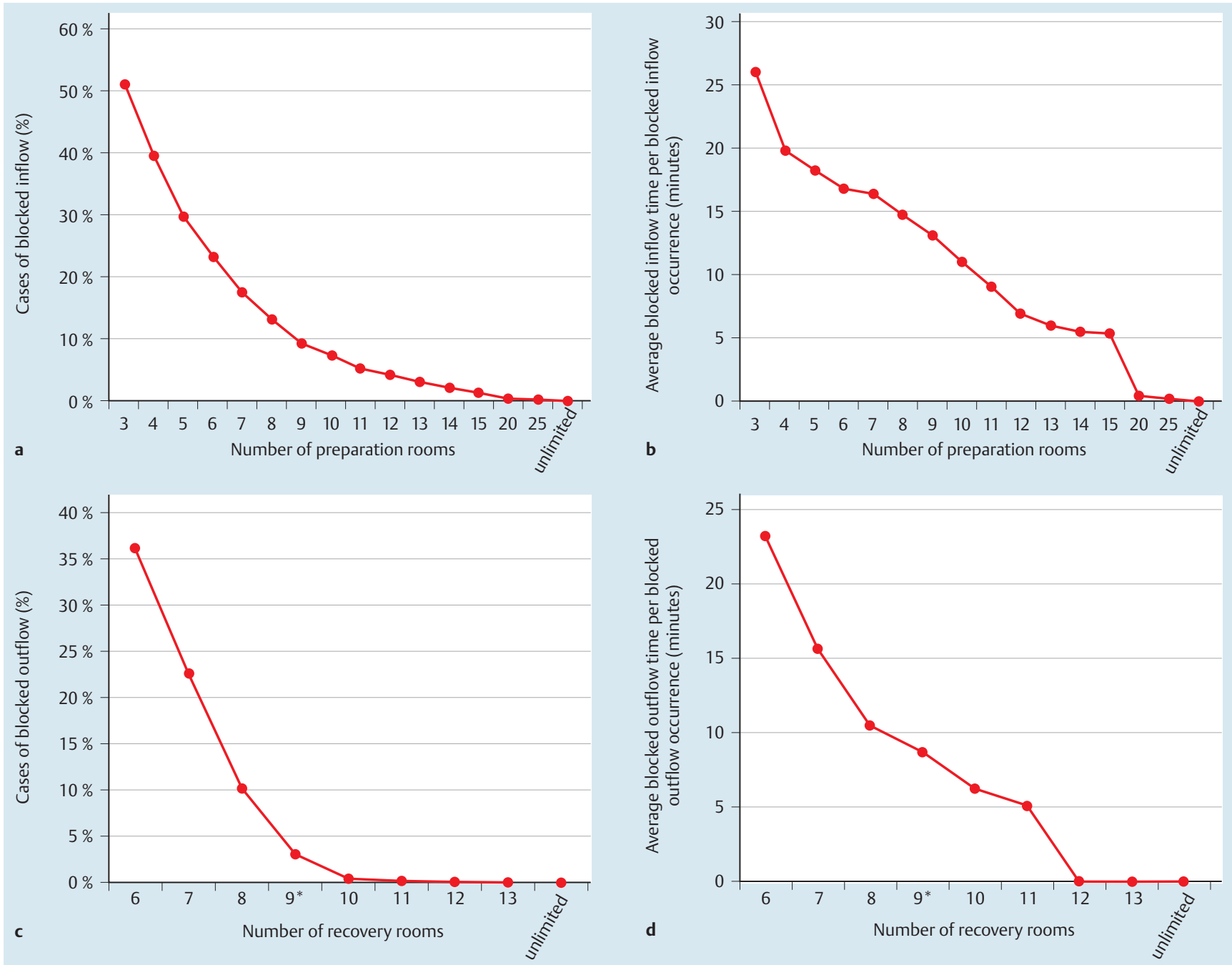

Fig. 2 a Percentage of blocked inflow occurrences as a function of number of preparation rooms. b Average blocked inflow time as a function of number of preparation rooms. $\mathbf{c}$ Percentage of blocked outflow occurrences as a function of number of recovery rooms. $\mathbf{d}$ Average blocked outflow time as a function of number of recovery rooms.

recovery/endoscopy room ratio of 1.8 (3.4 preparation/recovery rooms total per endoscopy room).

\section{Practical scenarios (Scenarios 1-5, 0 Table 3)}

Altering the scheduling of patients to perform EGDs as the first cases of the day decreased the blocked inflow events to $29 \%$ and resulted in slightly increased efficiency. Combining this with having the patients arrive earlier than the standard 30 minutes before the endoscopy further improved efficiency without significantly affecting the average patient time in the system (Scenario 3,० Table 3). Adding three additional preparation rooms, in combination with the changes in scheduling and patient arrival times, was the most efficient scenario tested, in which blocked inflow events occurred less than $15 \%$ of the time and reduced the average duration of blockage from 34 to 23 minutes (Scenario 5, 0 Table 3). However, with these changes, there was a modest increase in blocked outflow (from 3.5\% to 8.4\%) due to more efficient throughput, particularly earlier in the day.

\section{Other scenarios tested}

Numerous other scenarios were tested and were dominated by the scenarios presented in $\odot$ Table 3 or were considered not practical to execute. Examples of these include altering the physician to procedure room ratio (currently $1: 1$ with $1: 1.5$ and $1: 2$ also tested), scheduling half-days instead of full-days per physician, performing only one type of procedure for a particular day (i.e. performing only colonoscopies in all rooms on some days and only ERCP on other days), front-loading the schedule, splitting versus sharing the preparation and recovery resources, and assigning specific preparation/recovery rooms to procedure rooms.

\section{Theoretical scenario}

When all physical limitations were removed from the model, there were no episodes of blocked inflow or outflow as there were unlimited preparation and recovery rooms. However, as expected, the patient cycle time did increase as all patients arrived at 0700 to remove any patient-related limitations to efficiency.

\section{Additional advanced endoscopy room}

With the additional advanced endoscopy room, there were significantly more blocked outflow events (from $23 \%$ to $90 \%$ ) (৫ Table 4), indicating that recovery room space was inadequate. If we moved the paracentesis and liver biopsies out of the recov- 
Table 4 Metrics with addition of an additional procedure room devoted to advanced endoscopy.

\begin{tabular}{|c|c|c|c|}
\hline Key metrics & $\begin{array}{l}\text { Status } \\
\text { quo }\end{array}$ & $\begin{array}{l}\text { Additional } \\
\text { procedure } \\
\text { room }\end{array}$ & $\begin{array}{l}\text { Additional procedure } \\
\text { room without para- } \\
\text { centesis/liver biopsy }\end{array}$ \\
\hline $\begin{array}{l}\text { Patient cycle time from } \\
\text { prep to discharge, min }\end{array}$ & 182.9 & 205.5 & 192.8 \\
\hline $\begin{array}{l}\text { Average completion } \\
\text { time of last exam }\end{array}$ & 1702 & 1730 & 1655 \\
\hline $\begin{array}{l}\text { Blocked inflow (average } \\
\text { instances per day), \% }\end{array}$ & 32 & 31 & 33 \\
\hline $\begin{array}{l}\text { Average delay when } \\
\text { blocked inflow, min }\end{array}$ & 26.4 & 28.6 & 26.1 \\
\hline $\begin{array}{l}\text { Blocked outflow (aver- } \\
\text { age instances per day), \% }\end{array}$ & 23 & 90 & 21 \\
\hline $\begin{array}{l}\text { Average delay of blocked } \\
\text { outflow, min }\end{array}$ & 9.0 & 31.4 & 6.8 \\
\hline
\end{tabular}

ery space to a different location, the results returned to near status quo with the addition of the advanced endoscopy room. This validated the assessment that the space in recovery was not sufficient to allow for an additional endoscopy room.

\section{Discussion \\ $\nabla$}

In 1999, the Institute of Medicine (IOM) published the "To Err is Human: Building a Safer Health System" report that commenced the push for patient safety initiatives. This report concluded that errors are often caused by systems-based problems [15], yet relatively few resources have been devoted to improving or optimizing the operations of healthcare [16]. In 2001, the IOM released a second report entitled "Crossing the Quality Chasm" whereby they presented six quality aims - healthcare should be safe, effective, timely, patient-centered, efficient, and equitable [17]. Many of these six quality aims have seen focused attention over the past decade, with the exception of improving efficiency. A combined task force from the IOM and National Academy of Engineering developed recommendations on use of systems engineering tools to transform efficiency performance in healthcare as had been done previously in large-scale complex systems such as the manufacturing industry. Discrete event simulation is a powerful tool that can be applied in the patient, healthcare team, organization, and larger socioeconomic environment [16].

Despite the emphasis on systems-based learning and suggestions of systems engineering use, DES is underutilized in medicine and specifically gastroenterology. This study demonstrates a calculated approach to model an endoscopy unit and make specific changes to improve the efficiency of the care provided. By changing procedure scheduling and patient arrival times, the number of cases finished by 1700 could be increased with fewer blocked inflow events. When this was combined with modestly increasing the number of preparation and recovery rooms, utilization was improved. Furthermore, a sensitivity analysis on the adequate number of preparation and recovery rooms was performed. The number of combined preparation and recovery rooms per procedure room needed for efficient flow was 3.4. Additionally, the effect of changing an endoscopy unit structure was modeled. In our case, adding a procedure room caused a bottle- neck area (recovery rooms); therefore, attempts to address this deficiency can occur before implementation of the change.

In today's healthcare environment with the size of health networks ever increasing, and with increased competition for capital and resources among various units in a single health system, DES may identify inefficiencies that can be corrected without capital expenditures. As important, DES may also serve as a justification in some situations where investment in adequate resources is warranted to facilitate efficient care. Regardless, DES can be used to identify areas of inefficiency and model changes to the current "status quo" to improve the way care is delivered. As healthcare changes, an increased focus on value is necessary which encompasses both the quality of the care we provide but also the efficiency in which it is done [18].

Similar to the manufacturing industry, DES can be used in medicine to understand current areas of inefficiency and stimulate areas of change. However, unlike the manufacturing industry, medicine has numerous factors that are uncontrollable due to the uniqueness of each patient encounter; therefore, unrelenting standardization is not possible. Even under perfect operating conditions such as having an appropriate number of staff available, and eliminating any human factors that might contribute to inefficiencies (e.g., time lost in patient handoffs), there still remains unpredictable patient and procedural variables that preclude standardization. Despite these factors, DES can still be used to improve the efficiency of the care we provide in endoscopy.

There are several limitations to our study. First and foremost, results generated in a model may not necessarily transfer to improved efficiency when clinical changes are made. Furthermore, although our model was created and validated, it is dependent on adequate inputs which we attained in our 5 days of intense observation. Finally, our unit is unique in its design and processes; therefore, modeling of other endoscopy units will require the generation of a site-specific model. Despite this, these results are generalizable to a partial extent and more importantly, underscore how valuable a DES model is for any endoscopy center.

In conclusion, by applying discrete event simulation, we can model changes in an environment with complex interactions and find ways to improve the quality and efficiency of the medical care we provide. DES is an effective tool in devising strategies to optimize the daily efficiencies of endoscopy suites. Finally, DES is applicable to any endoscopy unit and would be particularly valuable to those who are trying to improve on the efficiency of care and patient experience.

Competing interests: Bryan Sauer: Cook Medical (Research study); Andy Wang: Cook Medical (Research study)

\section{References}

1 Kirch DG, Henderson MK, Dill MJ. Physician workforce projections in an era of health care reform. Annu Rev Med 2012; 63: 435-445

2 Rosenbaum S. The Patient Protection and Affordable Care Act: implications for public health policy and practice. Public Health Rep 2011; 126: $130-135$

3 Law AM, Kelton WD. Simulation modeling and analysis. 3rd edn. Boston: McGraw-Hill; 2000

4 Karnon J, Stahl J, Brennan A et al. Modeling using discrete event simulation: a report of the ISPOR-SMDM Modeling Good Research Practices Task Force-4. Med Decis Making 2012; 32: 701 - 711

5 Dexter F, Macario A, Traub RD et al. An operating room scheduling strategy to maximize the use of operating room block time: computer simulation of patient scheduling and survey of patients' preferences for surgical waiting time. Anesth Analg 1999; 89: 7-20 
6 Marcon E, Dexter F. Impact of surgical sequencing on post anesthesia care unit staffing. Health Care Manag Sci 2006; 9: 87-98

7 Tyler DC, Pasquariello CA, Chen CH. Determining optimum operating room utilization. Anesth Analg 2003; 96: 1114-1121

8 Stahl JE, Roberts MS, Gazelle S. Optimizing management and financial performance of the teaching ambulatory care clinic. J Gen Intern Med 2003; 18: 266 - 274

9 Berg B, Denton B, Nelson $H$ et al. A discrete event simulation model to evaluate operational performance of a colonoscopy suite. Med Decis Making 2010; 30: 380-387

10 Joustra PE, de Wit J, Struben VM et al. Reducing access times for an endoscopy department by an iterative combination of computer simulation and linear programming. Health Care Manag Sci 2010; 13: 17 26

11 Berg BP, Murr M, Chermak D et al. Estimating the cost of no-shows and evaluating the effects of mitigation strategies. Med Decis Making 2013; 33: 976-985
12 Gellad ZF, Taheri J, Burchfield D et al. Discrete event simulation modeling: a valuable tool to optimize endoscopy unit efficiency. Gastrointest Endosc 2012; 75: AB273-AB274

13 Day LW, Belson D, Dessouky $M$ et al. Optimizing efficiency and operations at a California safety-net endoscopy center: a modeling and simulation approach. Gastrointest Endosc 2014; 80: 762 - 773

14 Kopach-Konrad R, Lawley $M$, Criswell $M$ et al. Applying systems engineering principles in improving health care delivery. J Gen Intern Med 2007; 22: $03431-437$

15 Kohn LT, Corrigan JM, Donaldson MS (eds.) To err is human: building a safer health system. Washington, DC: National Academies Press; 2000

16 Reid PP, Compton WD, Grossman JH, Fanjiang G et al., eds. Building a better delivery system: a new engineering/health care partnership. Washington, DC: National Academies Press; 2005

17 Crossing the quality chasm: a new health system for the 21st century. Washington, DC: National Academies Press; 2001

18 Gellad ZF, Thompson CP, Taheri J. Endoscopy unit efficiency: quality redefined. Clin Gastroenterol Hepatol 2013; 11: 1046-1049.e1 